\title{
Understanding the bereavement experience of grandparents following the death of a grandchild from a life limiting condition: a meta-ethnography
}

Running head: GRANDPARENTS EXPERIENCE OF GRIEF

\author{
Michael J TATTERTON PhD MSc RNC RHV a, $\mathrm{b} *$ (Twitter: @MJTatterton) \\ Catherine WALSHE PhD RN ${ }^{\mathrm{b}}$ \\ (Twitter: @cewalshe)
}

${ }^{a}$ Martin House Children's Hospice, Grove Road, Boston Spa, Wetherby, West Yorkshire, LS23 6TX, UK

${ }^{\mathrm{b}}$ International Observatory on End of Life Care, Lancaster University, Furness Building, Lancaster, LA1 4YG, UK

Corresponding Author Contact details

* Email: MTatterton@martinhouse.org.uk

Author contributions:

\begin{tabular}{|l|l|}
\hline Criteria & Author Initials \\
\hline $\begin{array}{l}\text { Made substantial contributions to conception and design, or } \\
\text { acquisition of data, or analysis and interpretation of data; }\end{array}$ & MT CW \\
\hline $\begin{array}{l}\text { Involved in drafting the manuscript or revising it critically } \\
\text { for important intellectual content; }\end{array}$ & $\begin{array}{l}\text { MT drafted, MT and CW } \\
\text { revised }\end{array}$ \\
\hline $\begin{array}{l}\text { Given final approval of the version to be published. Each } \\
\text { author should have participated sufficiently in the work to } \\
\text { take public responsibility for appropriate portions of the } \\
\text { content; }\end{array}$ & MT CW \\
\hline $\begin{array}{l}\text { Agreed to be accountable for all aspects of the work in } \\
\text { ensuring that questions related to the accuracy or integrity } \\
\text { of any part of the work are appropriately investigated and } \\
\text { resolved. }\end{array}$ & MT CW \\
\hline
\end{tabular}

\section{Acknowledgements:}

We would like to express our thanks to Dr Sara Morris for her input, advice and guidance in undertaking this review, as a $\mathrm{PhD}$ supervisor for MT.

Conflict of interest statement:

No conflict of interest has been declared by the authors.

Funding statement: This review was completed as part of a $\mathrm{PhD}$, which received partial funding from Hospice UK and The RCN Foundation. 


\begin{abstract}
Aim: To increase understanding of grandparental grief following the death of a grandchild from a life-limiting condition, answering the question 'what is known about the experiences of grandparents following the death of a grandchild from a life-limiting condition?'

Design: Meta-ethnography

Data sources: A systematic literature search in Academic Search Complete, CINHAL, Embase, psycINFO, PubMed and Web of Science, supplemented by manual search strategies, were completed in 2015 and updated in May 2018.

Findings: Six papers that were included in the review. Eight themes were identified that describe the experience of grandparents, arranged into three superordinate themes: 'influence of the relationship with their grandchild', 'influence of the relationship with the grandchild's family' and 'pain'. The line of argument created offers a new interpretation of compounded grandparental grief. Many attributing factors of grandparent experience are present due to the multi-generational position held within the family. The multi-generational position of the grandparent, simultaneously occupying both parental and grandparental positions meant that individuals experienced emotional pain in witnessing the experience of those within the family.
\end{abstract}

Conclusion: There are many factors that contribute to the bereavement experience of grandparents, most of which are outside of their control. Grief is made more complicated by the multigenerational positions they hold within their family. The roles, positions and support needs of grandparents need to be acknowledged to improve the care and support available to better meet their needs as a parent, grandparent and individual who has experienced a child death. 
Key words: child; death; family centred care; family nursing; grandparents; metaethnography; nursing; paediatrics; palliative care; qualitative

\section{Impact:}

\section{What problem did the study address?}

- Grandparents are playing an increasing role in the care of children with life-limiting conditions.

- There are currently no published meta-syntheses that explore the experience of bereaved grandparents.

\section{What were the main findings?}

- Grandparents' identity fluctuates between parent and grandparent, with a primary drive of parenting.

- The intergenerational position of grandparents results in individuals experiencing emotional pain from witnessing the experience of those within their family.

- Grandparental experience of grief is a multifactorial construct and varies considerably in terms of intensity, depending on the nature of their relationship with the deceased child, their family and the circumstances that surround the death.

\section{Where and on whom will the research have an impact?}

- This review highlights the needs of grandparents within families, developing understanding of contemporary family.

- The research will impact on grandparents, improving the care and support available to better meet their needs as a parent, grandparent and individual. 
- The study is an example of why person-centred care is important, relevant to all fields of nursing. 
Understanding the Bereavement Experience of Grandparents Following the Death of a Grandchild from a Life-Limiting Condition: a Meta-Ethnography

\section{Background}

In the UK alone there are around 50,000 children living with a life-limiting condition (National Institute for Health and Care Excellence, 2016), which are the cause of 57\% of all deaths in childhood (Jarvis \& Fraser, 2018). Although global figures for the number of children with life-limiting conditions are not available, a study by Håkanson et al., (2017) identified 40,624 children aged between one and 17 years died in 11 European and nonEuropean counties, including Canada, Mexico, New Zealand, South Korea and the United States of America.

Little research has focused on the grief and bereavement experiences of grandparents. Grandparents play an important and increasing role in the lives of children affected by lifelimiting conditions and their family (Coall \& Hertwig, 2010). The grandparenting role has been described as both 'tenuous' and 'ambiguous' (Reitzes \& Mutran, 2004) due to few explicit norms in the role and function of grandparents in Western culture. Changes in Western society, such as mortality, fertility, higher divorce rates and greater proportion of mothers in employment, and proximity of living (Seltzer and Bianchi, 2013) mean that grandparents potentially have greater opportunities to fulfil grandparenting roles (Corsaro, 2014). The opportunity to fulfil the functions associated with grandparenthood can enhance the wellbeing of older adults, holding the position of a valued elder within the family, as well as providing a link to their past, in which they fulfilled a parenting role (Youngblut et al., 2010). Reitzes and Mutran (2004:pS213) note the unusual nature of role acquisition of grandparenthood, which is 'not dependent upon the actions of the person but on the fertility 
of one's children.' The unique position of grandparents within a family and the effect of this on their grief is widely acknowledged (Kohn and Moffitt, 2000; Potts, 2005; Young and Dowling, 2012).

Bereavement support is an integral element of children's palliative care, which enables families, as well as children themselves, to prepare for and cope with losses. Current understanding of the emotional support needs of grandparents is largely limited to the generalisation of work undertaken with parents, siblings and health workers (GilraneMcGarry and O'Grady, 2012). Frequently, grandparents are not often considered part of the 'bereaved family' when discussing bereavement (Nehari, Grebler and Toren, 2007), which this meta-ethnography aims to address.

Family centred care is a core principle of children's nursing; evolving over the last 60 years to reflect the social context of family, influenced by factors including changes in society, current government policy, research and development of the theoretical underpinnings of family centred care and the responses of parents and clinicians to family centred care (Smith \& Coleman, 2010). Although occasionally acknowledged in the inclusive definition of 'family' when discussing family centred care (Butler, Copnell, \& Willetts, 2014; Malcolm, Forbat, Knighting, \& Kearney, 2008; Richard \& Lyon, 2009), the specific needs of grandparents are not explored in current literature on family centred care.

The importance of considering context and its effect is well-established in social research. Although some work has been undertaken with grandparents that focuses on experiences of loss, this has not been from the perspective of those bereaved from grandchildren with life-limiting conditions. The nature of these conditions present a unique set of circumstances, shaping the experience of families, including, but not limited to, a high association with profound disability, the progressive nature of many of conditions, as well as the longevity and trajectory of life-limiting conditions in childhood. 


\title{
The Review
}

\begin{abstract}
Aim
To increase understanding of grandparental grief following the death of a grandchild from a life-limiting condition, answering the question: "what is known about the experiences of grandparents following the death of a grandchild from a life-limiting condition?"'
\end{abstract}

\section{Design}

Meta-ethnography is being used with increasing frequency to provide evidence of beliefs, experiences and understandings of complex social phenomena (France, Wells, Lang, \& Williams, 2016). Explanatory context of individual studies is often lost in the combining of qualitative studies (Barbour \& Barbour, 2003); a meta-synthetic approach enables the preservation of context (Thomas \& Harden, 2008; Toye et al., 2013), a central aim of this study.

The principles of the meta-ethnography reporting guidelines (France et al., 2015) (eMERGe) (http://emergeproject.org/) have been used to guide reporting of the process, finding and discussion.

\section{Inclusion and exclusion criteria}

The following selection criteria were used to determine the inclusion of papers in the review:

\section{Qualitative study design;}

2. Primary research studies; which detail findings from original research, rather than secondary analysis or meta-studies; 
3. Studies that explore experiences of grandchild loss from the perspective of those fulfilling a grandparental role, capturing the context and texture of the experience for their perspective;

4. Studies that focus on the death of grandchildren, and include deaths following a life-limiting condition, defined by the Association of Children's Palliative Care (ACT) and the Royal College of Paediatrics and Child Helath (RCPCH) (1997). Studies included data relating to children with life-limiting conditions, however it was not always the exclusive focus of the research.

The following exclusion criteria were applied:

1. Papers written in languages other than English, to prevent translation bias.

2. Studies which focused on perinatal deaths, or losses other than death.

\section{Search methods}

Six databases (psycINFO, PubMed, Web of Science, Academic Search Complete, CINHAL and Embase) were searched from inception until May 2018. The search terms are shown in table S1. Due to the nature of the research and the scant availability of published literature, an appeal for grey literature was made via PaedPalCare, an international emailbased forum which facilitates the sharing and exchange of approaches in children's palliative and hospice care. Despite the appeal for such literature, no additional works were identified. Only studies that met the inclusion criteria were included in the review.

\section{Search outcome}

A total of 129 papers were identified from searches and six papers were included in the synthesis; the reasons for exclusion are recorded in the PRISMA diagram (figure 1). 
Each paper was assessed to assure the conduct, validity of findings, transparency of process, and subsequent assessment of findings, as well as ensuring that they could be applied to the research question.

\section{Quality appraisal}

Identified papers were critically appraised using (CASP, 2018), containing a series of questions around validity, results and clinical relevance. All six papers were assessed by one reviewer (MT), illustrated in table S2. The quality appraisal did not highlight any information that led to the elimination of papers; three papers (Fry, 1997; Gilrane-McGarry \& O’Grady, 2011, 2012) included deaths resulting from conditions other than life-limiting conditions, however that did not alter the way these data were interpreted.

\section{Data abstraction and synthesis}

Synthesis began with the earliest published paper, progressing through the papers in chronological order of publication. Data were extracted from the sources electronically and entered into a database. No specialist software was utilised. Quality appraisal, data extraction, and initial synthesis was conducted by MT, and discussed extensively with CW and SM during academic supervision. MT coded the findings and discussion sections of included papers 'line by line' to develop descriptive themes. Quotes were extracted from research participants and researchers to support descriptive themes. These were then compared against included studies, to develop superordinate themes that moved beyond the findings of the primary studies to generate new and more comprehensive interpretations.

Determining how the studies are related. Details of contextualisation, which allow the interpretation and translation of themes of each study, has been facilitated by including key information about each study, as shown in table 1. To determine the relationships 
between studies, lists of themes (metaphors) were juxtaposed to determine the relationship, using a table to display concepts and themes across included studies, with an emphasis on developing superordinate themes, illustrated in table S3. Thematic analysis identified eight common and recurring themes, organised into three superordinate themes, shown in figure 2 . Discussion between the authors explored potential alternative explanations, to challenge individual interpretations and to develop themes. The data within each theme formed the basis for reciprocal translation, where key metaphors, themes or concepts found in one study were identified, and attempts made to translate these between studies. These were refined through discussion of how they are related.

Translating studies into each other. Table S3 summarises the core findings or theory from each paper, relevant to the research question. Understanding of the experiences of grandparents was developed further by translating the studies into each other, completed by using the themes identified in the first study, adding others as they emerged. Reciprocal translations enabled the development of a table, which explores cross-study comparison of the key themes, using quotes from participants of each study to explain the themes, shown in table 4.

Synthesising translations. On reviewing other published meta-ethnographies, it appears that authors arrive at synthesised translations in a variety of ways. In some, third order interpretations appeared to be derived from first and second order constructs reported in primary studies (Britten et al., 2002; Pound et al., 2005; Walter, Emery, Braithwaite, \& Marteau, 2004) but in most cases the process for doing this was not clearly defined. It appears to be accepted that the synthesis process, not unlike analysis in primary qualitative research, 'cannot be reduced to mechanistic tasks' (Atkins et al., 2008; Britten et al., 2002). 


\section{Findings: Expressing the translations}

Eight common and recurring themes were identified, which were organised into three superordinate themes, as illustrated in figure 2. The first superordinate theme represents grandparent's relationship with their grandchild before and during their death, and the influence on their bereavement experience. The second theme concerns the influence of the family on grandparental experience; focusing on the specific role of the grandparent within their family unit, and on wider family dynamics and how these can affect their experience. The final superordinate theme of pain refers to and amalgamates four recurrent themes, which explore factors that cause or exacerbate emotional pain in participating grandparents. These are 'disenfranchised grief', which includes status, acknowledgement and social positioning; 'bearing witness', which explores the effects of observing grief reactions of others in the family unit; 'cumulative pain' which explores the effects of fulfilling multiple familial roles, i.e. that of a grandparent to the deceased and surviving grandchildren, in addition to a parenting role and finally 'survivor guilt', which refers to the feelings of guilt that some participants expressed in outliving their grandchildren and defying 'natural order'.

\section{Influence of the relationship with their grandchild}

There is great diversity in the roles that grandparents play within families, both in terms of scope and intensity, which in turn affects the intensity of their bereavement experiences following the death of their grandchild. This point can be applied to many of the metaphors below, however Fry (1997) notes specifically that bereavement experiences of grandparents vary depending on the relationship with the grandchild before death. Other researchers reported similar phenomena, in specific situations. Two subordinate themes which relate to the influence of the grandparent/grandchild relationship, the grandparent/grandchild relationship, and the death itself, are explored below. 
Grandparent/grandchild relationship. Few studies focused on the experiences of grandparents during the child's illness, however love and despair during her grandchild's illness was expressed by participants in the study by Gilrane-McGarry and O'Grady (2011), and the deep affection that grandparents feel for their grandchildren were captured recurrently in the second study (Gilrane-McGarry and O'Grady, 2012). Gilrane-McGarry and O'Grady (2011:170) suggest that a 'unique and significant relationship often exists between grandparents and grandchild' and that due to the general increase in life expectancy, it is becoming more common for grandparents to experience the death of grandchild having reached adolescence, adding to the complexity of the grief, due to strong grandchildgrandparent friendships. The concept of friendship was implied in the study by Nehari et al. (2007) and the challenges that this created within grandparents, specifically the conflict between the expected protective role of a grandparent vs. honesty, valued in a friendship.

The death itself. Grandparental experiences of the time during and immediately following the death of a grandchild was not the focus of, nor explored in detail, in any of the studied included. However, the sudden impact of the death, despite the child's life-limiting illness was captured by Fry (1997) and Gilrane-McGarry and O'Grady (2011), capturing the complex emotions of grandparents at the time of death, including disbelief, hope, helplessness and bearing witness to their grandchild's death process.

An association of poor bereavement outcomes where the grandparents perceived poor quality end of life care was reported by Gilrane-McGarry and O'Grady (2011:173), identifying the pain caused by conflicting goals of different members of the family unit, where participants discussed feelings of relief, selfishness and sadness. 


\section{Influence of relationships within their family}

Grandparents' perception of their role within a family, and of the dynamics within the family have varying effects on the experience of grandparents, reported widely in the studies included. The two subthemes below represent the wider context of grief, highlighting the influence and contribution to the experiences of expressed pain.

Role within the family. Grandparents have an important function within the bereaved family (Nehari et al., 2007). This was a widely acknowledged element of the grandparent experience, mentioned by participants in all of the studies included. The role within the family can be further refined into two distinct contexts; the role that grandparents assume, and that which the family expect.

Multiple studies (Fry, 1997; Gilrane-McGarry and O'Grady, 2011; Moules et al., $2012 b$ ) found that grandparents were preoccupied with their efforts to reduce the pain of the child's parents, rather than with their own grief, with grandparents expressing a desire to take pain away from their children (Gilrane-McGarry and O'Grady, 2011). Grandparents showed an awareness of the complexity of their pain, whilst appreciating their dual role as both a grandparents and parent. Grandparenting experiences did not always focus on the sick child, but included taking a broader responsibility in meeting the needs of the family. The perception of 'being needed' within a family could have a positive effect on the experiences of grandparents (Fry, 1997); equally, grandparents with a less-defined role following the death of a grandchild expressed sadness in relation to their function, stating that they felt 'surplus to requirements' (Gilrane-McGarry and O'Grady, 2012:181). These feelings were in addition to the sadness they felt following their frandchild's death.

A stark contrast in the role of grandparents before and after the death of the child was apparent across the studies. Grandparents described active roles in the care of their 
grandchild during their illness, which was perceived by some grandparents to change following death (Gilrane-McGarry and O'Grady, 2012). This perceived lack of role exacerbates the grief experience; prior to the death, grandparents focus on the needs of the family, rather than their personal needs. The removal of a specific role or function, which follows the death of their grandchild can lead to the grandparent having to address their own feelings of grief, due to the lack of distraction. This is compounded further by their perception of being distanced from the family in which they had previously held a significant, meaningful and active role.

Family dynamics. The death of a grandchild had profound and wide-ranging effects of the experience of grandparents, from bringing families closer together (Gilrane-McGarry \& O’Grady, 2012; Moules et al., 2012b) to creating tension, strain and emotional distance throughout the family (Nehari et al., 2007). This was reported to fluctuate throughout the child's illness, during and following death. Nehari et al. (2007) found that the death of a grandchild affected the emotional relationship with surviving grandchildren, where one participant disclosed feeling 'afraid to love' the deceased child's sibling. The death of a grandchild also affects dynamics outside of the child's immediate family, including the parents and siblings of grandparents (Moules et al., 2012b). The act of believing their own emotional needs as secondary to those of the child's immediate family places grandparents under 'extraordinary physical, mental, and emotional strain' (Gilrane-McGarry and O'Grady, 2011:171). Some grandparents found strength and support within their marriages or personal relationships (Moules et al., 2012). 
Pain

Pain was the most prolifically discussed metaphor throughout the studies and one that could be broadly applied to almost all findings. Four discrete metaphors are explored below: disenfranchised grief, bearing witness, cumulative pain and survivor guilt; however there is a clear link between these representations and a convergence of boundaries between each of them, each having an effect on the other.

Disenfranchised grief. Disenfranchised grief, a phenomenon that results from others failing to appreciate a person's experience of bereavement, was widely discussed by participants across all studies and can be further divided into subcategories: society's perception and disenfranchisement exacerbated by grandparents themselves.

The altruism displayed by grandparents, always as parents themselves (Moules et al., 2012b), endeavour to protect their children and surviving grandchild by suppressing their own grief and pain (Fry, 1997). Their ability to provide continuing support to the family and their age and experience (Gilrane-McGarry and O'Grady, 2011), meant that grandparents could be perceived as immune from intense grief and therefore requiring less support. These assumptions were reinforced by participants, who discussed a responsibility to provide strength, or to shield parents from additional stress by concealing their own worries, fears and problems (Moules et al., 2012b)

A failure to acknowledge the feelings and experiences of grandparents was seen outside of the family too, including that by professionals involved in the care of the dying child. Grandparents talked about not feeling that they, their role or their issues were 'as important', and that professionals involved in the care of their grandchild would gently acknowledge them, before 'turning away' (Moules et al., 2012a:123). 
Bearing witness. Bearing witness to their grandchild's illness and death, their desire to protect their children and their inability to do so was a recurrent cause of emotional pain discussed in all included studies. The act of watching and subsequent helplessness in being unable to take the pain away from their child caused immense emotional pain (GilraneMcGarry and O'Grady, 2012), the full extent of which was often not disclosed to parents in an effort to protect their children, exacerbating their disenfranchisement further (Moules et al. (2012b). In addition to the pain caused by the death of their grandchild, grandparents also feel pain in their capacity as a parent, which was recurrently expressed alongside a desire to take the pain away, and resulting sense of helplessness (Gilrane-McGarry and O'Grady, 2011).

Existing research suggests that the experience of bearing witnesses is a multifaceted phenomenon that surrounds the witnessing of multiple individuals within their family. The above quotes demonstrate that 'grandparents' are not only fulfilling a grandparenting role, but also experience the loss from the perspective of a parent.

Cumulative pain. The concept of cumulative pain was highlighted to varying degrees in each of the studies included, including the suggestion of double (Reed, 2000) or triple pain, expressing witnessing the suffering of their child and grandchild (Moules et al. (2012b). The synthesis of findings from each of the included studies suggests that cumulative pain is more complex than simply grieving for multiple generations, but that there are other cumulative factors that influence grandparents' experiences. These include subsequent changes in their son or daughter (Gilrane-McGarry and O'Grady, 2011).

In addition to pain caused through bearing witness and perceived helplessness, their feelings of social isolation caused by a lack of perceived social recognition in addition to the change in role (Nehari et al., 2007). The compounding of these factors can create an 
overwhelming sense of insurmountable pain and emotional disorientation (Gilrane-McGarry and O’Grady, 2012).

Survivor guilt. A number of participants across studies expressed a perception of guilt and unfairness in surviving their grandchildren, which in turn added to their experience of emotional pain (Fry, 1997). In the majority, the expression to die in place of their grandchild appears to be due to their desire to correct the 'natural order' or generational death, however some participants suggested that to die would be a way to avoid the pain associated with the death of a grandchild (Gilrane-McGarry and O'Grady, 2011).

\section{Discussion}

Six studies that explored the bereavement experience of grandparents following the death of a grandchild from a life-limiting condition were identified. Guided by the principles of Noblit and Hare (1988), a line of argument was developed, drawing on inferences from the translation process to express the findings of this meta-ethnography. Similarities and differences between studies were integrated, synthesising a new interpretation that fits across studies. The synthesis is expressed in three superordinate themes: the intergenerational relationship between grandchild and grandparent, the influence of the family and emotional pain.

There are clear similarities in grief responses to childhood death by parents and grandparents (White, 2002), and those who have experienced perinatal deaths (Black, Howard, \& Bakewell-Sachs, 2011; Currie et al., 2016; Wood \& Modi, 2014). However, Ponzetti (1992) found that these were expressed less often by grandparents. The findings suggest that grandparental experience of grief is a multifactorial construct and varies considerably in terms of intensity, depending on the nature of their relationship with the 
deceased child, their family and the circumstances that surround the death. A synthesis of translations concluded that many of the attributing factors of the grandparent experience are present due to their multigenerational position within the family, occupying dual the positions of both grandparent and parent.

Families have been shown to have a substantial influence on the bereavement experiences of grandparents; not least as they gatekeep (Reitzes \& Mutran, 2004; Stelle, Fruhauf, Orel, \& Landry-Meyer, 2010) the amount and quality of contact between the grandparent and grandchild, and the rest of the family. Similar findings have been reported in research surrounding stillbirths and neonatal deaths; Murphy and Jones (2014) reported that following a neonatal death, parents distanced themselves from grandparents, due to a lack of support and understanding and feelings of intergenerational resentment (O'Leary, Warland, \& Parker, 2011), or strengthened ties due to the support the parents received from the wider family.

Reciprocal translation provided new insights into the social positioning of grandparents within the family, highlighted by multiple participants and at varying stages throughout their experience, from recognition or diagnosis of a life-limiting condition, to the family's bereavement. Murphy and Jones (2014) link social positioning and identity, reporting that parents struggle with their identity following perinatal death, and that there has been little research conducted on similar identity transitions to grandparenthood. Relationships within the family have shown to have a significant effect on the experiences of grandparents (Young and Dowling, 2012).

Translation across the studies identified that the relationship between grandparents and their sick grandchild affected the way individuals experienced death, where grandparents who had close, regular contact with grandchildren experienced the greatest emotional pain. This correlates with findings in research with bereaved parents, where parents of older 
children experienced higher levels of long-term grief, attributed to the growth of affectional bonds between parents and their children (Van Der Geest et al., 2014). By contrast, a study by (Cacciatore, Defrain, \& Jones, 2008) described the 'invisible death' of stillborn infants, arguing that despite the absence of a physical presence, the much anticipated, psychological presence of a baby results in parents and family members experiencing emotional pain for many years after the loss. Gender differences and coping were not highlighted in this synthesis, research with parents suggests that unlike males, bereaved females value the opportunity to talk about their grief within their family support network (Hawthorne, Youngblut, \& Brooten, 2016). The impact of effective multigenerational relationships manifested in numerous forms, like ripples throughout the experience of individuals. Grandparents who perceived themselves as occupying a fulfilling role within a family, where they felt valued experienced a sense of control, belonging and support. Correlating findings have been reported in research with parents of neonates and children, where better bereavement outcomes are seen where parents have been able to maintain a sense of control (Dias, Docherty, \& Brandon, 2017) and involvement (Van Der Geest et al., 2014).

Emotional pain was a recurrent element of grandparenting experience, highlighted across the studies. Reciprocal translation showed that the intergenerational position of the grandparent, simultaneously occupying both parental and grandparental positions meant that individuals experienced emotional pain in witnessing the experience of those within the family. Grandparents talked extensively of witnessing the experience of their children.

Line of argument synthesis was used to develop insight into the experience of bearing witness, and the association with helplessness - each phenomenon following the other. Grandparents discussed the anguish of seeing the pain in their own children, but feeling powerless to help them; similar findings were reported in parents (Currie et al., 2016; Van Der Geest et al., 2014). Comprehension of this was mixed - some grandparents appeared to 
accept the inevitability of parental pain, accepting it as an unavoidable element of the grieving process; others really struggled in not being able to take away or 'make better' the emotional pain of their children. The intensity of the perception on helplessness correlated with the quality of multigenerational relationships; those with effective relationships perceived less helplessness.

The concept of pain, and more specifically cumulative pain was cited widely with elements of pain highlighted across most metaphors. Translation across studies suggest that pain extends beyond the generational considerations already discussed, to include other cumulative variables, the most commonly expressed of which is witnessing the suffering of the child's parents and disenfranchisement. Similarities can be drawn with research surrounding children with complex needs and intellectual disabilities. Todd (2007) highlights the complicated grief experience of those caring for children with complex needs, reporting a heightened sense of losses surrounding identity, support network, and those around them failing to recognise the impact of the death of a disabled child. Disenfranchisement, or failure to recognise grief is discussed widely in bereavement literature. Murphy and Jones (2014) compare grandparents to fathers and siblings in referring to 'forgotten mourners' and the 'vicarious knowers' of the unborn, deceased infant. Disenfranchisement can occur when grief is recognised but not acknowledged, owing to an assumption that grandparents can cope with loss more easily (Woodroffe, 2013). Neonatal literature suggests that parents can contribute to a sense of disenfranchisement, when they unaware that grandparents can grieve for their neonatal grandchild who has died (Murphy \& Jones, 2014). This demonstrates the complexity and multifaceted aspects of disenfranchisement. 


\section{Strengths and limitations of the review}

This is the first published meta-synthesis of studies relating to the experience of bereaved grandparents. Although individual elements of pain have previously been described separately in published papers, the line of argument created offers a new interpretation of compounded grandparental grief. Only published papers written in English were considered for inclusion, which may have discounted research written in other languages. Of the six papers included in this meta-ethnography, three included grandchildren that had died from causes other than life-limiting conditions (Fry, 1997; Gilrane-McGarry and O'Grady, 2011; 2012). It follows that the findings, discussion and conclusions of these papers present a broader perspective of grandchild death, which should be noted when considering the findings of this meta-ethnography. Thus, the findings of this review should be considered as stimuli for further enquiry, rather than an end in itself (Hubbard, McLachlan, Forbat, \& Munday, 2012). It is possible that the findings may not be relevant to non-English speaking cultures. Given the known association between complex health needs and children with lifelimiting conditions, the fact that the experience of grandparents of children with complex health needs was not explored in any of the primary studies constitutes a limitation of the present synthesis.

\section{Research implications}

Further research is needed on the experiences of grandparents, with particular focus on the contextual implications of childhood life-limiting conditions (Fraser et al., 2012), which include complex health needs and profound disability (Noyes et al., 2013). Existing literature demonstrates that grandparents are playing a significant role within families through the provision of various support, including financial, practical and emotional assistance to their children and grandchildren; yet the effect of this on grandparents has not 
been explored in detail, particularly from the perspective of those in a grandparenting role. Research should focus on meaning making, in addition to the effects of grandchild death on relationships within the family and how these evolve throughout the experience.

\section{Clinical implications}

Family centred care is a fundamental principle of children's nursing. This study highlights the extent of the multiple, cross-generational roles played by grandparents of children with life-limiting conditions, and their families and brings into focus the impact of the conflicting roles and expectations of grandparents by their family and the extent to which these contribute to their experience. In order to meet the needs of grandparents, their dual, simultaneous multigenerational roles of both a parent and grandparent must acknowledged and enabled. Family-centred care planning can be improved to accommodate the perspectives of family members, which identify the contributions and roles of individuals within the family, in addition to their support needs. Support for grandparents should focus on the definition and negotiation of role, particularly the challenges of meeting the needs of themselves and their family, simultaneously fulfilling the roles of a parent and grandparent.

\section{Policy implications}

There are currently no policies relating specifically to grandparents of children with life-limiting conditions in the UK. This study adds to the evidence surrounding grandparent need, developing understanding of both the roles and needs of grandparents, which can inform the development of policies that reflect the diverse and multifaceted roles of grandparenting. The findings of this study suggest that grandparents need to be supported during their grandchild's illness in a similar way to parents and siblings pre-bereavement (Blackburn, 2010). 


\section{Conclusion}

Grandparental grief is often not recognised with the family, their social network or by professionals; this disenfranchisement exacerbates the experience of emotional pain, which was expressed in all studies, and across all metaphors. There are many factors that contribute to the experience of grandparents, many of which are outside of their control, which is made more complicated by the multigenerational positions they hold within their family. The roles, positions and support needs of individuals need to be acknowledged, improving the care and support available to better meet their needs as a parent, grandparent and individual who has experienced a child death. 


\section{References}

ACT/RCPCH. (1997). A guide to the development of children's palliative care services. Bristol, UK.

Atkins, S., Lewin, S., Smith, H., Engel, M., Fretheim, A., \& Volmink, J. (2008). Conducting a meta-ethnography of qualitative literature: lessons learnt. BMC Medical Research Methodology, 8(21), 21. http://doi.org/10.1186/1471-2288-8-21

Barbour, R. S., \& Barbour, M. (2003). Evaluating and synthesizing qualitative research: the need to develop a distinctive approach. Journal of Evaluation in Clinical Practice, 9(2), 179-186. http://doi.org/10.1046/j.1365-2753.2003.00371.x

Black, B. P., Howard, E., \& Bakewell-Sachs, S. (2011). The evolving science of care in perinatal loss. The Journal of Perinatal \& Neonatal Nursing, 25(1), 1-2. http://doi.org/10.1097/JPN.0b013e3182074757

Blackburn, M. (2010). Children's hospice care from March 2009 to September 2010: a report based on visits to all children's hospice services in the UK. Bristol.

Britten, N., Campbell, R., Pope, C., Donovan, J., Morgan, M., \& Pill, R. (2002). Using meta ethnography to synthesise qualitative research: a worked example. Journal of Health Services Research \& Policy, 7, 209-215. http://doi.org/10.1258/135581902320432732

Butler, A., Copnell, B., \& Willetts, G. (2014). Family-centred care in the paediatric intensive care unit: an integrative review of the literature. Journal of Clinical Nursing, 23(15-16), 2086-99. http://doi.org/10.1111/jocn.12498

Cacciatore, J., Defrain, J., \& Jones, K. L. C. (2008). When a baby dies: Ambiguity and stillbirth. Marriage and Family Review, 44(4), 439-454.

http://doi.org/10.1080/01494920802454017

Coall, D. a, \& Hertwig, R. (2010). Grandparental investment: past, present, and future. The Behavioral and Brain Sciences, 33(1), 1-19; discussion 19-40. 
http://doi.org/10.1017/S0140525X09991105

Corsaro, W. A. (2014). The Sociology of Childhood. Thosand Oaks, CA: Sage Publications Inc.

Critical Appraisal Skills Programme. (2018). 10 Questions To Help You Make Sense of Qualitative Research. http://doi.org/10.1371/journal.pmed.0040323

Currie, E. R., Christian, B. J., Hinds, P. S., Perna, S. J., Robinson, C., Day, S., \& Meneses, K. (2016). Parent Perspectives of Neonatal Intensive Care at the End-of-Life. Journal of Pediatric Nursing, 31(5), 478-489. http://doi.org/10.1016/j.pedn.2016.03.023

Dias, N., Docherty, S., \& Brandon, D. (2017). Parental bereavement: Looking beyond grief. Death Studies, 41(5), 318-327. http://doi.org/10.1080/07481187.2017.1279239

France, E. F., Ring, N., Noyes, J., Maxwell, M., Jepson, R., Duncan, E., ... Uny, I. (2015). Protocol-developing meta-ethnography reporting guidelines (eMERGe). BMC Medical Research Methodology, 15(1), 1-14. http://doi.org/10.1186/s12874-015-0068-0

France, E. F., Wells, M., Lang, H., \& Williams, B. (2016). Why, when and how to update a meta-ethnography qualitative synthesis. Systematic Reviews, 5(1), 1-12. http://doi.org/10.1186/s13643-016-0218-4

Fraser, L. K., Miller, M., Hain, R., Norman, P., Aldridge, J., McKinney, P. a, \& Parslow, R. C. (2012). Rising National Prevalence of Life-Limiting Conditions in Children in England. Pediatrics, 129(4), e923-929. http://doi.org/10.1542/peds.2011-2846

Fry, P. S. (1997). Grandaprents' reactions to the death of a grandchild: an exploratory factor analytic study. Omega, 35(1), 119-140.

Gilrane-McGarry, U., \& O’Grady, T. (2011). Forgotten grievers: an exploration of the grief experiences of bereaved grandparents (part one). International Journal of Palliative Nursing, 17(4), 170-176. Retrieved from http://search.ebscohost.com/login.aspx?direct=true $\& \mathrm{db}=\mathrm{a} 9 \mathrm{~h} \& \mathrm{AN}=75454768 \&$ site $=$ ehos 
t-live

Gilrane-McGarry, U., \& O'Grady, T. (2012). Forgotten grievers: an exploration of the grief experiences of bereaved grandparents (part 2). International Journal of Palliative Nursing, 18(4), 179-187. Retrieved from http://search.ebscohost.com/login.aspx?direct=true $\& d b=a 9 h \& A N=75454768 \&$ site $=$ ehos t-live

Håkanson, C., Öhlén, J., Kreicbergs, U., Cardenas-Turanzas, M., Wilson, D. M., Loucka, M., ... Cohen, J. (2017). Place of death of children with complex chronic conditions: cross-national study of 11 countries. European Journal of Pediatrics, 176(3), 327-335. http://doi.org/10.1007/s00431-016-2837-0

Hawthorne, D. M., Youngblut, J. A. M., \& Brooten, D. (2016). Parent Spirituality, Grief, and Mental Health at 1 and 3 Months After Their Infant's/Child's Death in an Intensive Care Unit. Journal of Pediatric Nursing, 31(1), 73-80. http://doi.org/10.1016/j.pedn.2015.07.008

Hayslip, B., \& White, D. L. (2008). The grief of grandparents. In M. Stroebe, R. Hansson, H. Schut, \& W. Stroebe (Eds.), Handbook of bereavement research and practice: advances in theory and intervention. American Psychological Association.

Hubbard, G., McLachlan, K., Forbat, L., \& Munday, D. (2012). Recognition by family members that relatives with neurodegenerative disease are likely to die within a year: a meta-ethnography. Palliative Medicine, 26(2), 108-22. http://doi.org/10.1177/0269216311402712

Jarvis, S., \& Fraser, L. K. (2018). Comparing routine inpatient data and death records as a means of identifying children and young people with life-limiting conditions. Palliative Medicine, 32(2), 543-553. http://doi.org/10.1177/0269216317728432

Kohn, I., \& Moffitt, P. L. (2000). Bereaved Grandparents. In A silent sorrow: pregnancy loss: 
guidance and support for you and your family. London: Routledge.

Malcolm, C., Forbat, L., Knighting, K., \& Kearney, N. (2008). Exploring the experiences and perspectives of families using a children's hospice and professionals providing hospice care to identify future research priorities for children's hospice care. Palliative Medicine, 22(8), 921-8. http://doi.org/10.1177/0269216308098214

Moules, N. J., McCaffrey, G., Laing, C. M., Tapp, D. M., \& Strother, D. (2012). Grandparents' experiences of childhood cancer, part 2: the need for support. Journal of Pediatric Oncology Nursing : Official Journal of the Association of Pediatric Oncology Nurses, 29(3), 133-40. http://doi.org/10.1177/1043454212439627

Murphy, S., \& Jones, K. S. (2014). By the way knowledge: Grandparents, stillbirth and neonatal death. Human Fertility, 17(3), 210-213. http://doi.org/10.3109/14647273.2014.930190

National Institute for Health and Care Excellence. (2016). End of life care for infants, children and y young people with life-limiting conditions: planning and management (NICE guideline NG61). London: NICE.

Nehari, M., Grebler, D., \& Toren, A. (2007). A voice unheard: grandparents grief over children who died of cancer. Mortality, 12(1), 66-78. http://doi.org/10.1080/13576270601088475

Noyes, J., Edwards, R. T., Hastings, R. P., Hain, R., Totsika, V., Bennett, V., ... Lewis, M. (2013). Evidence-based planning and costing palliative care services for children: novel multi-method epidemiological and economic exemplar. BMC Palliative Care, 12(1), 18. http://doi.org/10.1186/1472-684X-12-18

O’Leary, J., Warland, J., \& Parker, L. (2011). Bereaved parents' perception of the grandparents' reactions to perinatal loss and the pregnancy that follows. Journal of Family Nursing, 17(3), 330-56. http://doi.org/10.1177/1074840711414908 
Ponzetti, J. (1992). Bereaved families: a comparison of parents' and grandparents' reactions to the death of a child. OMEGA - Journal of Death and Dying, 25(1), 63-71.

Potts, S. (2005). Cornerstones - supporting bereaved grandparents. In Everylife: death, bereavement and life through the eyes of children, parents and practitioners. Wiltshire: APS Publishing.

Pound, P., Britten, N., Morgan, M., Yardley, L., Pope, C., Daker-White, G., \& Campbell, R. (2005). Resisting medicines: a synthesis of qualitative studies of medicine taking. Social Science \& Medicine (1982), 61(1), 133-55. http://doi.org/10.1016/j.socscimed.2004.11.063

Reed, M. L. (2000). Grandparents cry twice: help for bereaved grandparents. USA: Baywood Publishing.

Reitzes, D. C., \& Mutran, E. J. (2004). Grandparent identity, intergenerational family identity, and well-being. The Journals of Gerontology. Series B, Psychological Sciences and Social Sciences, 59(4), S213-9. http://doi.org/59/4/S213 [pii]

Richard, \& Lyon, M. E. (2009). Adolescent end-of-life decision making: Family-centered advance care planning. In J. L. Werth Jr. \& D. Blevins (Eds.), Decision making near the end-of-life: Issues, developments, and future directions. (pp. 11-25). New York, NY US: Routledge/Taylor \& Francis Group. Retrieved from http://search.ebscohost.com/login.aspx?direct=true \&db=psyh\&AN=2007-18826002\&site $=$ ehost-live

Seltzer, J. a., \& Bianchi, S. M. (2013). Demographic Change and Parent-Child Relationships in Adulthood. Annual Review of Sociology, 39(1), 275-290. http://doi.org/10.1146/annurev-soc-071312-145602

Smith, L., \& Coleman, V. (Eds.). (2010). Child and family-centred healthcare: concept, theory and analysis (2nd Editio). Baisingstoke, UK: Palgrave Macmillan. 
Stelle, C., Fruhauf, C. a, Orel, N., \& Landry-Meyer, L. (2010). Grandparenting in the 21st century: issues of diversity in grandparent-grandchild relationships. Journal of Gerontological Social Work, 53(8), 682-701. http://doi.org/10.1080/01634372.2010.516804

Thomas, J., \& Harden, A. (2008). Methods for the thematic synthesis of qualitative research in systematic reviews. BMC Medical Research Methodology, 8, 45. http://doi.org/10.1186/1471-2288-8-45

Todd, S. (2007). Silenced grief: living with the death of a child with intellectual disabilities. Journal of Intellectual Disability Research : JIDR, 51(Pt 8), 637-48. http://doi.org/10.1111/j.1365-2788.2007.00949.x

Toye, F., Seers, K., Allcock, N., Briggs, M., Carr, E., Andrews, J., \& Barker, K. (2013). "Trying to pin down jelly" - exploring intuitive processes in quality assessment for meta-ethnography. BMC Medical Research Methodology, 13, 46. http://doi.org/10.1186/1471-2288-13-46

Van Der Geest, I. M. M., Darlington, A. S. E., Streng, I. C., Michiels, E. M. C., Pieters, R., \& Van Den Heuvel-Eibrink, M. M. (2014). Parents' experiences of pediatric palliative care and the impact on long-term parental grief. Journal of Pain and Symptom Management, 47(6), 1043-1053. http://doi.org/10.1016/j.jpainsymman.2013.07.007

Walter, F. M., Emery, J., Braithwaite, D., \& Marteau, T. M. (2004). Lay Understanding of Familial Risk of Common Chronic Diseases : A Systematic Review and Synthesis of Qualitative Research, 583-594. http://doi.org/10.1370/afm.242.INTRODUCTION

White, D. (2002). Partners in grief: Parent-grandparent relationships following infant loss. Gerontologist, 42, 67.

Wood, D., \& Modi, N. (2014). Practical guidance for the management of palliative care on neonatal units, (February). 
Woodroffe, I. (2013). Supporting bereaved families through neonatal death and beyond.

Seminars in Fetal and Neonatal Medicine, 18(2), 99-104.

http://doi.org/10.1016/j.siny.2012.10.010

Young, C., \& Dowling, T. (2012). Grandparents, extended family and friends. In Parents and bereavement: a personal and professional exploration of grief. Oxford, UK: Oxford University Press.

Youngblut, J. M., Brooten, D., Blais, K., Hannan, J., \& Niyonsenga, T. (2010). Grandparent's health and functioning after a grandchild's death. Journal of Pediatric Nursing, 25(5), 352-9. http://doi.org/10.1016/j.pedn.2009.02.021 